\title{
Intercorrência entre leucose enzoótica e tuberculose em bovinos abatidos em frigorífico
}

\section{Intercurrence between enzootic leukosis and tuberculosis in slaughtered bovine in slaughterhouses}

\author{
Gabriela Bim Ramos ${ }^{\text {* }}$, Dayane Olímpia Gomes ${ }^{1}$, Mariana Assunção de Souza', \\ Nadia Grandi Bombonato', Anna Monteiro Correia Lima ${ }^{2}$
}

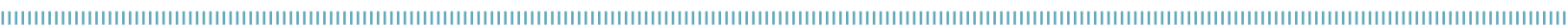

RESUMO: Leucose e tuberculose são doenças que acometem o rebanho bovino e acarretam consideráveis prejuízos econômicos, em virtude do impacto na produtividade, porém há poucos relatos de que elas ocorram concomitantemente. Diante disso, objetivou-se avaliar a intercorrência entre essas doenças em bovinos abatidos no município de São Gotardo, MG, sendo que esses animais foram reagentes à tuberculinização e apresentaram lesóes características da doença durante o abate sanitário. Cento e trinta e três amostras de soro sanguíneo, todas oriundas de bovinos positivos para tuberculose, foram analisadas pela técnica de imunodifusão em gel de ágar (IDGA), e a prevalência de bovinos que apresentaram positividade ao teste de IDGA foi de 55,64\% (74/133). Os resultados obtidos nesta pesquisa permitiram concluir que a tuberculose e a leucose são doenças presentes nas regiōes estudadas e encontram-se disseminadas na população avaliada, com níveis significativos, causando risco à saúde dos animais e das pessoas, dado o caráter zoonótico da tuberculose bovina.

PALAVRAS-CHAVE: zoonose; tuberculinização; linfossarcoma; IDGA; bovina.

\begin{abstract}
Leukosis and tuberculosis are diseases that affect cattle and entail considerable economic losses, due to theim pact on productivity, but there are few reports that they occur simultaneously. Therefore, aimed to evaluate the complications of these diseases in cattles laughtered in São Gotardo, MG, these animals were positive to the tuberculin and showed lesions characteristic of the disease during the stamping. One hundred and thirty three samples of blood serum, all from positive to bovine tuberculosis, were analyzed by immuno diffusion technique in agar gel (AGID), and the prevalence of cattle that were positive by AGID test was $55.64 \%(74 / 133)$. The results of this research showed that tuberculos is and leukosis are diseases present in the studied regions and are disseminated in this population, with significant levels, causing risk to the health of animals and people, as the zoonotic bovine tuberculosis.
\end{abstract}

KEYWORDS: zoonosis; tuberculin; lymphosarcoma; AGID; bovine.

'Programa de Pós-graduação em Ciências Veterinárias, Faculdade de Medicina Veterinária, Universidade Federal de Uberlândia (UFU) - Uberlândia (MG), Brasil. 'Laboratório de Doenças Infectocontagiosas, Faculdade de Medicina Veterinária, UFU - Uberlândia (MG), Brasil.

*Autor correspondente: gabivetufu@yahoo.com.br

Recebido em: 10/02/2014. Aceito em: 05/01/2016 
A leucose enzoótica bovina (LEB) e a tuberculose bovina (TB) são doenças infectocontagiosas caracterizadas pela evolução crônica e pelos grandes prejuízos que determinam à pecuária bovina, estabelecendo sucessivas condenaçôes de carcaças em matadouros e restringindo o comércio de animais, além de aumentar os custos com serviços veterinários (OIE, 2008).

No Brasil, a leucose foi descrita pela primeira vez por RANGEL; MACHADO (1943), que realizaram um levantamento sobre a frequência de neoplasias nos animais domésticos, no estado de Minas Gerais, e assinalaram a ocorrência de linfossarcomas em bovinos; entretanto, somente em 1959, no Rio Grande do Sul, МеRCKT et al. registraram oficialmente o primeiro diagnóstico clínico da doença.

É uma enfermidade neoplásica, causada por um retrovírus que possui um longo período de incubação (dois a cinco anos); sua origem ocorre no tecido linfoide e é frequentemente diagnosticada nos animais domésticos (Jones et al., 2000), infectando, preferencialmente, linfócitos B (GofF, 2007). A infecção natural ocorre em bovinos, capivaras, bubalinos e ovinos (CAmargos et al., 2004); em bovinos, é conhecida também como linfossarcoma, linfoma maligno, linfomatose e leucemia bovina (BARROs, 2007).

Pode ocasionar linfocitose persistente (LP), linfossarcoma ou apresentar-se de forma inaparente, porém, o animal é portador e disseminador do vírus. É uma doença negligenciada devido à pequena quantidade de animais clinicamente afetados, e é comumente diagnosticada pela presença de anticorpos em amostras de soro ou leite, sendo que os anticorpos são detectados no soro de animais dentro de duas a oito semanas pós-infecção (Troiano, 2009).

Tal enfermidade causa imunossupressão, responsável pelas infecçôes secundárias, e os animais podem ser descartados precocemente, antes da ocorrência de sintomas (Troiano, 2009). A forma clínica manifesta-se, principalmente, em animais adultos destinados à produçáo leiteira, pois em rebanhos leiteiros existe maior quantidade de animais adultos do que em rebanhos de corte. Quanto mais intensivo o manejo, maior o risco de se transmitir a doença (Radostits et al., 2002).

A LEB é registrada nos cinco continentes do mundo (OLSON; Miller, 1987). No Brasil, a infecção pelo vírus da leucose bovina (VLB) ocorre em praticamente todas as regióes do país, e a última avaliação sobre a disseminação da doença revelou uma prevalência nacional de 27,6\% (BIRGEL JúNior et al., 2006).

$\mathrm{O}$ método atualmente utilizado para detecção de animais infectados no Brasil é a imunodifusão em gel de ágar (IDGA), um teste específico, mas náo muito sensível, sendo utilizado para amostras individuais de soro ou plasma sanguíneo (OIE, 2004). Para a pesquisa de anticorpos em amostras de leite, utiliza-se a técnica de ELISA, visto que tem alta sensibilidade (SARDi et al., 2002).

Atualmente não há nenhuma vacina efetiva que confira proteção contra o VLB bem como tratamento viável e efetivo (BIRGEL JÚNIOR et al., 2006). No Brasil, não existem programas específicos para a prevenção e o controle dessa enfermidade. $\mathrm{O}$ controle e a erradicação consistem na adoçáo de medidas tais como identificação, isolamento e eliminação dos animais reagentes (SiLva et al., 2008). Os mesmos autores afirmaram, ainda, que a realizaçâo de testes sorológicos nos animais com idade superior a seis meses, com repetiçáo semestral, permite identificar os animais positivos e auxiliar no controle da doença.

Em relação à TB, é uma doença infectocontagiosa que afeta seres humanos e outras diversas espécies animais. Segundo Roxo (1996), tal enfermidade tem evolução extremamente lenta e caquetizante, acarretando perdas na produtividade do rebanho, contaminação das crias e condenaçáo dos animais ao abate, sendo necessárias melhorias nos aspectos de saúde pública veterinária.

A principal espécie infectante para os bovinos é o Mycobacterium bovis, que ocorre no mundo todo e, além de constituir um grave problema de saúde pública, seus prejuízos representam significativas barreiras econômicas (BRASIL, 2006). É endêmica no Brasil e afeta a economia por reduzir a produtividade do rebanho, e pelas perdas de carcaça em frigorífico. $\mathrm{O}$ agente é transmitido para os humanos, principalmente por meio do consumo do leite e derivados crus (Murakami et al., 2009). A redução da incidência da doença é possível caso sejam utilizadas as medidas de controle e abate de animais positivos, segundo o Programa Nacional de Controle de Erradicação da Brucelose e Tuberculose Animal (PNCEBT) (CASTRO et al., 2009).

A hipótese da intercorrência entre essas duas enfermidades baseia-se na associaçáo à etiopatogenia e em dois fatores que podem interferir de forma interdependente: o manejo sanitário a que são submetidos os rebanhos e as características imunológicas do VLB (Mendes et al., 2011).

Com o intuito de verificar a intercorrência entre duas doenças infectocontagiosas no Triângulo Mineiro e Alto Paranaíba, o objetivo deste estudo foi investigar a ocorrência de bovinos soropositivos para LEB, a partir de amostras de soro sanguíneo de animais reagentes à tuberculinizaçáo.

Esta pesquisa foi conduzida de acordo com normas e aprovação do Comitê de Ética no Uso de Animais (CEUA) da Universidade Federal de Uberlândia (UFU), sob o protocolo no 113/12.

Cento e trinta e três bovinos foram abatidos, todos com tuberculose diagnosticada a partir do teste cervical comparativo, sendo 117 fêmeas e 16 machos, adultos, mestiços leiteiros, oriundos de 5 propriedades rurais do Alto Paranaíba e Triângulo Mineiro no Frigorífico Frisago - Frigorífico Ltda. (Serviço de Inspeção Estadual no 3957), de São Gotardo, MG, de acordo com normatizaçáo do PNCEBT.

Não foi realizado nenhum teste laboratorial para confirmar a presença do Mycobacterium bovis.

No momento da sangria, foi colhida uma amostra de sangue de cada animal, em tubo siliconizado sem anticoagulante, com capacidade de $10 \mathrm{~mL}$. Tais amostras foram identificadas e transportadas, sob refrigeração, até o Laboratório de Doenças Infectocontagiosas da Faculdade de Medicina Veterinária da UFU.

O soro, obtido após a centrifugação das amostras por 5 minutos a $3.000 \mathrm{x}$ g, foi conservado em temperatura de $-20^{\circ} \mathrm{C}$ até a realização dos testes diagnósticos. 
O diagnóstico de LEB, por meio da detecção de anticorpos séricos anti-VLB, foi realizado pela prova de IDGA, teste de referência preconizado pela Office International des Épizooties (OIE) por ter alta especificidade, além de ser viável e acessível (TosTes, 2005). O antígeno utilizado para diagnóstico foi produzido pelo Instituto Tecnológico do Paraná (TECPAR), segundo metodologia preconizada pelo fabricante.

Foram confeccionadas lâminas de vidro $25 \times 76 \mathrm{~mm}$ com 4,5 mL de solução de agarose (1 g de ágar Noble dissolvido em 100 mL de solução tampão) e, após seu resfriamento, perfuraram-se rosetas com 7 poços, com $4 \mathrm{~mm}$ de diâmetro cada, distanciadas, no máximo, $3 \mathrm{~mm}$ entre si.

$\mathrm{O}$ poço central foi preenchido com $25 \mu \mathrm{L}$ do antígeno. Ao redor dele foram colocadas as amostras de soro testadas, na quantidade de $25 \mu \mathrm{L}$, e os demais poços, também alternados, foram preenchidos com $25 \mu \mathrm{L}$ de soro controle positivo. Após esse procedimento, as lâminas foram incubadas em temperatura ambiente $\left(20 \mathrm{a} 25^{\circ} \mathrm{C}\right)$ em câmara úmida.

Os bovinos foram classificados em positivos e negativos, conforme a interpretação do teste, que foi feita com o auxílio de um foco de luz forte, a fim de verificar o aparecimento das linhas de precipitação entre antígeno e soro, observadas após 24, 48 e $72 \mathrm{~h}$ de incubação (Fig. 1). Os resultados foram expressos por meio do cálculo de percentual simples (SIEGEL, 1975).

Neste estudo, evidenciou-se a intercorrência entre duas doenças: uma bacteriana e outra viral, TB e LEB, respectivamente.

A ocorrência da leucose foi de 55,64\% (74/133), valor intermediário aos encontrados por outros autores. $\mathrm{O}$ percentual de animais soropositivos para leucose varia consideravelmente entre os Estados (Tabela 1). LeITE et al. (1984) encontraram uma prevalência de 70,9\% em Minas Gerais.

Vale salientar que foram utilizadas amostras de soro sanguíneo provenientes de bovinos de cinco propriedades rurais e, em uma delas, Aniceto (2007) registrou 26\% de bovinos positivos para leucose. A diferença é que esse resultado

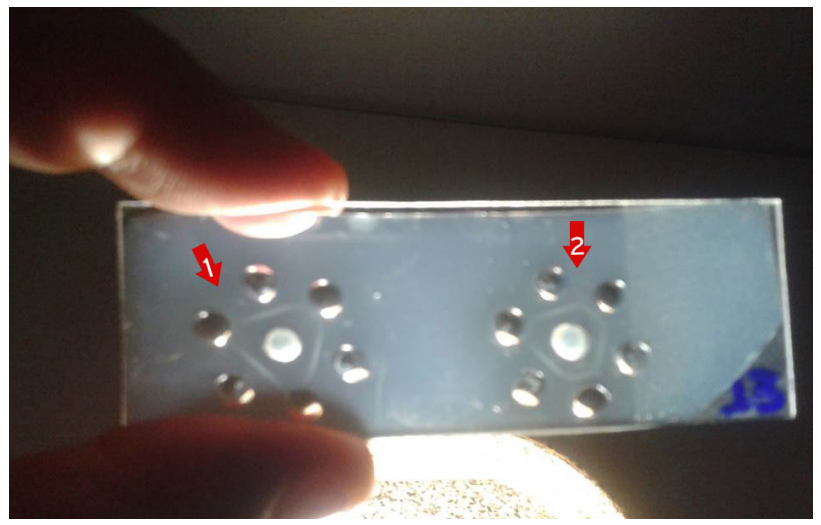
Fonte: arquivo pessoal (2012).

Figura 1. Teste de imunodifusão em gel de ágar, mostrando as reações negativa (seta 1 ) e positiva (seta 2 ) de amostras de soro de animais abatidos em São Gotardo, MG, 2012. foi obtido pela contagem de linfócitos, e não pela técnica de IDGA, utilizada no estudo em questão.

Em relação à tuberculose, as notificaçóes oficiais indicaram uma prevalência média nacional de 1,3\% de animais infectados entre os testados, entre os anos de 1989 e 1998 (Brasil, 2006); entretanto, esses dados são referentes a animais sujeitos a testes regulares, não sendo representativos da populaçáo bovina nacional (VELOSO, 2014).

Com o objetivo de estimar a prevalência da tuberculose bovina na população, vários estudos foram realizados em diferentes Estados (Tabela 2).

Tabela 1. Frequência da leucose enzoótica bovina em diversos estados brasileiros.

\begin{tabular}{|c|c|c|}
\hline Estados & $\begin{array}{c}\text { Frequência } \\
\text { (\%) }\end{array}$ & Fonte \\
\hline Acre & 9,7 & ABREU et al., 1990 \\
\hline Bahia & 16,1 & TAVORA, 1990 \\
\hline Ceará & 9,1 & ABREU, 1993 \\
\hline Goiás & 35,9 & ANDRADE; ALMEIDA, 1991 \\
\hline $\begin{array}{l}\text { Mato Grosso } \\
\text { do Sul }\end{array}$ & 22,0 & CAMARgos et al.,2000 \\
\hline Minas Gerais & 28,4 & SANTOS et al., 1985 \\
\hline Pará & $26,0-49,8$ & MOLNAR et al., 1999 \\
\hline Paraná & 20,5 & KANTEK et al., 1983 \\
\hline Pernambuco & 15,1 & Melo, 1992 \\
\hline $\begin{array}{l}\text { Rio Grande } \\
\text { do Sul }\end{array}$ & 9,2 & MORAES et al., 1996 \\
\hline Rio de Janeiro & 54,3 & ROMERO; ROWE, 1981 \\
\hline Rondônia & 23,0 & ABREU et al., 1990 \\
\hline São Paulo & 54 & D'ANGELINo et al., 1998 \\
\hline Sergipe & 8,8 & Melo et al., 1997 \\
\hline
\end{tabular}

Fonte: adaptado de Assis; Camargos, 2007.

Tabela 2. Estimativa da prevalência da tuberculose bovina em alguns estados brasileiros.

\begin{tabular}{|c|c|c|c|}
\hline & Estimativa (\%) & Estimativa (\%) & \\
\hline Estados & $\begin{array}{l}\text { Prevalência } \\
\text { geral de } \\
\text { rebanhos } \\
\text { positivos para } \\
\text { tuberculose** }\end{array}$ & $\begin{array}{c}\text { Fêmeas e } \\
\text { machos } \\
\geq 24 \text { meses } \\
\text { positivos para } \\
\text { tuberculose** }\end{array}$ & Fonte \\
\hline $\begin{array}{l}\text { Minas } \\
\text { Gerais }\end{array}$ & 5,02 & 0,8 & $\begin{array}{c}\text { BELCHIOR } \\
(2000)\end{array}$ \\
\hline Paraná & 2,15 & 0,42 & $\begin{array}{c}\text { SILVA } \\
(2012)\end{array}$ \\
\hline $\begin{array}{l}\text { Mato } \\
\text { Grosso }\end{array}$ & 1,3 & 0,123 & $\begin{array}{l}\text { NÉSPOLI } \\
\text { (2012) }\end{array}$ \\
\hline Bahia & 1,6 & 0,21 & $\begin{array}{c}\text { CostA } \\
(2012)\end{array}$ \\
\hline
\end{tabular}

**intervalo de confiança de $95 \%$ 
A LEB e a TB são doenças comumente detectadas no animal vivo, com base nos testes da IDGA e da tuberculina (OIE, 2008), sendo que o primeiro demonstra alta especificidade, adequada sensibilidade e grande praticidade, sendo pouco dispendioso (Mammerickx et al., 1987). O teste da tuberculina é aferido como de significativa especificidade para bovinos (Roxo, 1996).

Ao comparar o número de bovinos positivos para a leucose, dentre os reagentes para a tuberculose, concluiu-se que ambas as doenças estão disseminadas nesse rebanho, e que a infecção simultânea de muitos animais sugere que o vírus da LEB pode desempenhar algum papel no desencadeamento da TB, resultados que corroboram os estudos de Mendes et al. (2011).

A intercorrência entre as duas doenças já foi registrada por Melo (1999), em rebanhos do estado de São Paulo, e por Melo et al. (2010), Fernandes et al. (2011), Mendes et al. (2011) e Batista Filho (2012), em rebanhos do estado de Pernambuco, o que demanda atenção de pesquisadores e autoridades sanitárias.

Embora a maioria dos animais infectados não apresente sintomatologia, a leucose gera perdas econômicas consideráveis (RAJÃo, 2008), e tais animais atuam como fonte de infecção para indivíduos sadios, lembrando que infecção e doença representam um mesmo risco na cadeia epidemiológica (Mendes et al., 2011).

Muscoplat et al. (1974), Wyers (1975) e Castro et al. (1988) afirmaram que o papel do VLB no desencadeamento de bacterioses oportunistas de importância clínico-epidemiológica e em saúde pública, como a tuberculose, é desconhecido.

Assim, não é possível determinar qual doença aconteceu primeiro, porém deve-se refletir que o animal, uma vez acometido, torna-se imunodeprimido, ficando vulnerável a novas infecçóes, sem condiçôes de combatê-las, principalmente se a doença em questáo for a LEB, visto que desorganiza o sistema imunológico do animal e pode não desenvolver sintomas que indiquem a sua ocorrência (NASCIMENTO, 2011).

Diante dos resultados obtidos, foi constatado que houve intercorrência entre leucose e tuberculose, e que essas doenças encontram-se nos rebanhos estudados, destacando-se a leucose, que apresentou níveis significativos (55,64\%). Assim, torna-se essencial maior vigilância dos rebanhos, com a adoção e implantação de medidas sanitárias rigorosas, a fim de controlar a disseminação do vírus e, consequentemente, evitar perdas na cadeia produtiva da bovinocultura. Além disso, pessoas que lidam com bovinos merecem atenção, dado o caráter zoonótico da tuberculose.

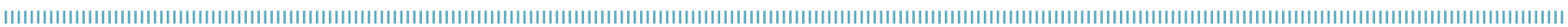
REFERÊNCIAS

\begin{abstract}
ANICETO, F.M. Pesquisa de linfocitose persistente e exame citológico para diagnóstico de Leucose Bovina na Fazenda Do Glória, em Uberlândia - MG. Brasil. 2007. 37f. Monografia (Graduação em Medicina Veterinária) - Faculdade de Medicina Veterinária, Universidade Federal de Uberlândia, Uberlândia, 2007.
\end{abstract}

ASSIS, R.A.; CAMARGOS, M.F. Leucose Enzoótica Bovina. 2007. Disponível em: <http://www.beefpoint.com.br/radares-tecnicos/ sanidade/leucose-enzootica-bovina-36191/>. Acesso em: 09 jan. 2014.

BARROS, C.S.L. Leucose Bovina, In: RIET-CORREA, F.; SCHILD A.L.; LEMOS, R.A.A.; BORGES, J.R.J. Doenças de ruminantes $e$ equídeos. 3 ed. Santa Maria: Pallotti, 2007. p.159-169.

BATISTA FILHO, L.C.F. Análise leucométrica em bovinos tuberculinizados e sua aplicação no monitoramento da LeucoseEnzoótica em rebanhos do estado de Pernambuco. 2012. 62p. Dissertação (Mestrado em Ciência Veterinária) - Universidade Federal Rural de Pernambuco, Recife, 2012.

BIRGEL JÚNIOR, E.H.; DIAS, W.M.C.; SOUZA, R.M.; POGLIANI, F.C.; BIRGEL, E.H. Prevalência da infecção pelo vírus da Leucose dos bovinos em animais da raça Simental, criados no Estado de São Paulo. ARS Veterinária, v.22, n.2, p.122-129, 2006.

BRASIL. Ministério da Agricultura, Pecuária e Abastecimento. Departamento de Defesa Animal. Programa Nacional de
Controle e Erradicação da Brucelose e Tuberculose. Manual Técnico. 2006. 184p.

CAMARGOS, M.F.; REIS, J.K.P.; LEITE, R.C. Bovine leukemia virus. Virus: reviews and research. Journal of the Brazilian Society for Virology, v.9, n.1, p.44-59, 2004.

CASTRO, N.H.C.; WALTER. J.; SANTOS, R.C.S. dos; D'ANGELINO, J.L.; BENESI, F.; BIRGEL, E.H.; BEÇAK, W. Cytogenetics study of cattle affected by persistent lymphocytosis. Journal of Veterinary Medicine, v.35, p.380-384, 1988.

CASTRO, K.G.; LIEVORE J.P.M.; CARVALHO, G.D. Tuberculose bovina: diagnóstico, controle e profilaxia. PUBVET, v.3, n.30, ed. 91, art. 648, 2009.

FERNANDES, A.C.C.; TENÓRIO, T.G.S.; MENDES, E.I.; SILVA, T.I.B.; MELO, L.E.H. de. Leucose enzoótica e tuberculose dos bovinos: estudo retrospectivo e prospectivo da ocorrência em rebanhos leiteiros do estado de Pernambuco. Veterinária e Zootecnia (UNESP), v.18, n.4, p.728-732, 2011.

GOFF, S.P. Retroviridae: the retroviruses and their replication. In: KNIPE, D.M.; HOWLEY, P.M. Fields virology. 5 ed. Philadelphia: Lippincott Williams and Wilkins, 2007. v.2. p.1999-2069.

JONES, T.C. Patologia veterinária. 6 ed. São Paulo: Manole, 2000. p. 1415. 
LEITE, R.C.; MODENA, C.M.; MOREIRA, E.C.; ABREU, J.J. Evolução clínica da Leucose Enzoótica Bovina. Arquivo Brasileiro de Medicina Veterinária e Zootecnia, v.36, n.1, p.47-57, 1984.

MAMMERICKX, M. The immunodiffusion test for the detection of Bovine Leukemia Virus infected animals. In: BURNY, A.; MAMMERICKX, M. (Eds.). Enzootic bovine leukosis and bovine leukemia virus. Boston: Martinus Nijhoff, 1987. p.195-200.

MELO, L.E.H. Avaliação da Intercorrência entre LeucoseEnzoótica, Tuberculose e Leptospirose dos bovinos em rebanhos produtores de leite C do Estado de São Paulo. Tese (Doutorado) - Universidade de São Paulo, São Paulo, 1999.

MELO, L.E.H.; FERNANDES, A.C.C.; SILVA, T.I.B.; TENÓRIO, T.G.S. MENDES, E.I; BAPTISTA FILHO, L.C.F. Estudo retrospectivo e prospectivo da intercorrência entre leucose enzoótica e tuberculose dos bovinos em rebanhos leiteiros do estado de Pernambuco. In: Seminário Nacional sobre Brucelose e Tuberculose Animal (SNBTA), 2010. Anais... Belo Horizonte, 2010.

MENDES, E.I.; MELO, L.E.H.; TENÓRIO, T.G.S.; SÁ, L.M.; SOUTO, R.J.C.; FERNANDES, A.C.C.; SANDES, H.M.M.; SILVA, T.I.B. Intercorrência entre Leucose Enzoótica Bovina e Tuberculose em bovinos leiteiros do Estado de Pernambuco. Arquivos do Instituto Biológico, v.78, n. 1, p.1-8, jan./mar. 2011

MERCKT, H.; GIUDICE, J.C.O.; MULLER, J.A. Leucose bovina: concepção moderna e primeira verificação da doença no Rio Grande do Sul. Revista da Escola de Agricultura e Veterinária UFRGS, v.2, n.3, p.7-19, 1959.

MURAKAMI, P.S.; FUVERKI, R.B.N.; NAKATANI, S.M.; BARROS FILHO, I.R.de;BIONDO, A.W.Tuberculose bovina: saúde animal e saúde pública. Arquivos de Ciências Veterinárias e Zoologia da Unipar, v.12, n.1, p.67-74, 2009.

MUSCOPLAT, C.C.; ALHAJI, I.; JOHNSON, D.W.; POMEROY,.KA.; OLSON J.M.; LARSON, V.L.; STEVENS, J.B.; SORENSEN, D.K. Characteristics of lymphocyte responses to phytomitogens: comparison of responses of lymphocytes from normal and lymphocytotic cows. American Journal of Veterinary Research, v.35, n.8, p.1053-1055, 1974.

NASCIMENTO, V.R. Intercorrência de quatro doenças infectocontagiosas que acometem bovinos. 2011 . 30f. (Graduação em Medicina Veterinária) - Faculdade de Medicina Veterinária, Universidade Federal de Uberlândia, Uberlândia, 2011.

OIE - OFFICE INTERNATION DES ÉPIZOOTIES. Manual of Diagnostic Tests and Vaccines for Terrestrial Animals mammals, birds, bees. 5 ed. Paris: OIE 2004. Cap. 2,3,4. Enzootic Bovine Leukosis.

OIE - OFFICE INTERNATIONAL DES ÉPIZOOTIES. Código Zoosanitário Internacional. 2008. Disponível em: <http://www. oie.int>. Acesso em: 08 nov. 2013.
OLSON, C.; MILLER, I. History and terminology of enzootic bovine leukosis. In: BURNY, A.; MAMMERICKX, M. ed. Enzootic bovine leukosis and bovine leukemia virus. Boston: Martinus Nijhoff, 1987, p.3-11.

RADOSTITS, O.M.; GAY, C.C.; BLOOD, D.C.; HINCHCLIFF, K.W. Clínica Veterinária: um tratado de doenças dos bovinos, ovinos, suínos, caprinos e equinos. 9 ed. Rio de Janeiro: Guanabara Koogan, 2002. p.940-951.

RAJÃO, D.S. Efeito da infecção pelo vírus da leucose enzoótica bovina na produção de leite e reprodução de rebanhos leiteiros.2008. 26p. Dissertação (Mestrado em Medicina Veterinária Preventiva) - Escola de Veterinária, Universidade Federal de Minas Gerais, Belo Horizonte, 2008.

RANGEL, N.M.; MACHADO, A.V. Contribuição à oncologia comparada em Minas Gerais. Arquivos Escola Superior de Medicina Veterinária do Estado de Minas Gerais, v.1, p.83-96, 1943.

ROXO, E. Tuberculose Bovina: Revisão. Arquivos do Instituto Biológico, v.63, n.2, p.91-97, 1996

SARDI, S.I.; CAMPOS, G.S.; BARROS, S.B.; EDELWEISS, G.L.; MARTINS, D.T. Revista de Ciências Médicas e Biológicas, v. 1, n. 1, p.61-65, nov. 2002

SIEGEL, S. Estatística no paramétrica. México: Trillos, 1975.

SILVA, R.C.; FONTANA, I.; MEIRELLES, F.C.; RUGGIERO, A.P.M.; BENATO, N.; BORGES, J.R.J. Ocorrência de leucose enzoótica bovina na forma de linfomas no Distrito Federal: relato de caso. Arquivos do Instituto Biológico, v.75, n.4, p.507-512, 2008.

TECPAR ${ }^{\circ}$ Instituto de tecnologia do Paraná. Antígeno para diagnóstico de Leucose Enzoótica Bovina.

TOSTES, R.A. Situação da Leucose Bovina no Brasil: uma revisão. Colloquium Agrarie, n. 1, p.42-50, set. 2005.

TROIANO, L.D.C. Produção e caracterização de anticorpos monoclonais anti-gp51 do vírus Leucose Bovina (VLB). 2009. $101 \mathrm{f}$. Dissertação (Mestrado em Processos Biotecnológicos, área de concentração: saúde animal e humana) - Setor de Tecnologia, Universidade Federal do Paraná, Curitiba, 2009.

VELOSO, F.P. Prevalência e fatores de risco da tuberculose bovina no Estado de Santa Catarina. 2014. 31 p. Dissertação (Mestrado em Saúde Animal) - Faculdade de Agronomia e Medicina Veterinária, Universidade de Brasília, Brasília, 2014.

WYERS, M. Rappelsur lesoncorna virus des animaux. Recueil de Médecine Vétérinaire, v.151, n.3, p.153-163, 1975. 